\title{
Natural Gas as a Fuel Option for Heavy Vehicles
}

James E. Wegrzyn and Wai Lin Litzke

Brookhaven National Laboratory

Michael Gurevich

U.S. Department of Energy 
SAE routinely stocks printed papers for a period of three years following date of publication. Direct your orders to SAE Customer Sales and Satisfaction Department.

Quantity reprint rates can be obtained from the Customer Sales and Satisfaction Department.

To request permission to reprint a technical paper or permission to use copyrighted SAE publications in other works, contact the SAE Publications Group.

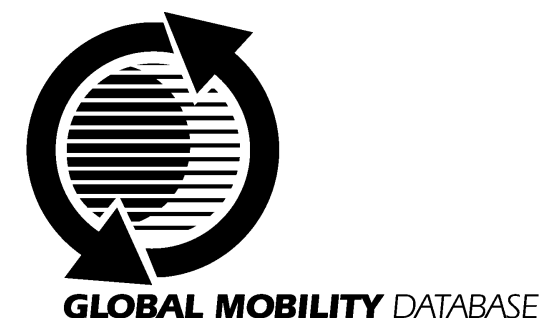

AII SAE papers, standards, and selected books are abstracted and indexed in the Global Mobility Database

\section{ISSN 0148-7191}

Positions and opinions advanced in this paper are those of the author(s) and not necessarily those of SAE. The author is solely responsible for the content of the paper. A process is available by which discussions will be printed with the paper if it is published in SAE Transactions. For permission to publish this paper in full or in part, contact the SAE Publications Group.

Persons wishing to submit papers to be considered for presentation or publication through SAE should send the manuscript or a 300 word abstract of a proposed manuscript to: Secretary, Engineering Meetings Board, SAE.

\section{Printed in USA}




\title{
Natural Gas as a Fuel Option for Heavy Vehicles
}

\author{
James E. Wegrzyn and Wai Lin Litzke \\ Brookhaven National Laboratory \\ Michael Gurevich \\ U.S. Department of Energy
}

\begin{abstract}
The U.S. Department of Energy (DOE), Office of Heavy Vehicle Technologies (OHVT) is promoting the use of natural gas as a fuel option in the transportation energy sector through its natural gas vehicle program [1]. The goal of this program is to eliminate the technical and cost barriers associated with displacing imported petroleum. This is achieved by supporting research and development in technologies that reduce manufacturing costs, reduce emissions, and improve vehicle performance and consumer acceptance for natural gas fueled vehicles. In collaboration with Brookhaven National Laboratory, projects are currently being pursued in (1) liquefied natural gas production from unconventional sources, (2) onboard natural gas storage (adsorbent, compressed, and liquefied), (3) natural gas delivery systems for both onboard the vehicle and the refueling station, and (4) regional and enduse strategies. This paper will provide an overview of these projects highlighting their achievements and current status. In addition, it will discuss how the individual technologies developed are being integrated into an overall program strategic plan.
\end{abstract}

\section{INTRODUCTION}

The nation's dependency on foreign petroleum sources is growing. This is primarily due to the strong demand for liquid petroleum-based fuels by the transportation sector. On-road vehicles in 1998 used about 8.5 million barrels per day (MMbbl/day) of petroleum fuel [2]. It is projected that usage will increase to over $11 \mathrm{MMbbl} /$ day by the year 2020 with essentially all of the increase attributed to trucks. The growing demand for the transport of goods and products is a reason for this increase in energy use by trucks. Thus, a viable trucking industry and a secure supply of fuel are necessary for maintaining growth in the gross domestic product.
Natural gas is both domestically abundant and cleanburning. Therefore, to address the need for clean and domestic sources of fuel the U.S. DOE is pursuing the development of natural gas for the transportation sector. The DOE-OHVT is developing energy efficient, cleanburning natural gas engines [3] that can meet stringent emission standards. For heavy vehicles that must transport goods interstate, liquefied natural gas (LNG) is being considered as an alternative fuel to diesel because it can provide trucks with the long driving range [4]. Hence, developing LNG technology and market strategies for trucks and buses are ways to meet the nation's goals for economic expansion, air quality improvement, and energy security.

\section{DOE/BNL PROGRAM STRUCTURE}

The Natural Gas Vehicle Program developed at Brookhaven National Laboratory (BNL) and sponsored by the U.S. DOE OHVT consists of contracting with private industry and nonprofit organizations to conduct research and development in natural gas utilization. The DOE/BNL program plan is specifically aimed at achieving cost reductions and improved performance of natural gas vehicles and refueling stations by supporting R\&D in liquid natural gas production, storage and refueling systems. Elements of the plan include the following: (1) eliminating evaporative greenhouse gas emissions; (2) recovering $25 \%$ of the energy of liquefying and transporting natural gas; (3) increasing onboard fuel storage capacity by $40 \%$ for compressed natural gas (CNG) and $25 \%$ for LNG; and (4) developing a safe, low-pressure adsorbent natural gas storage system. The following sections summarize the DOE/BNL projects in terms of their objectives, progress and achievements to date. 


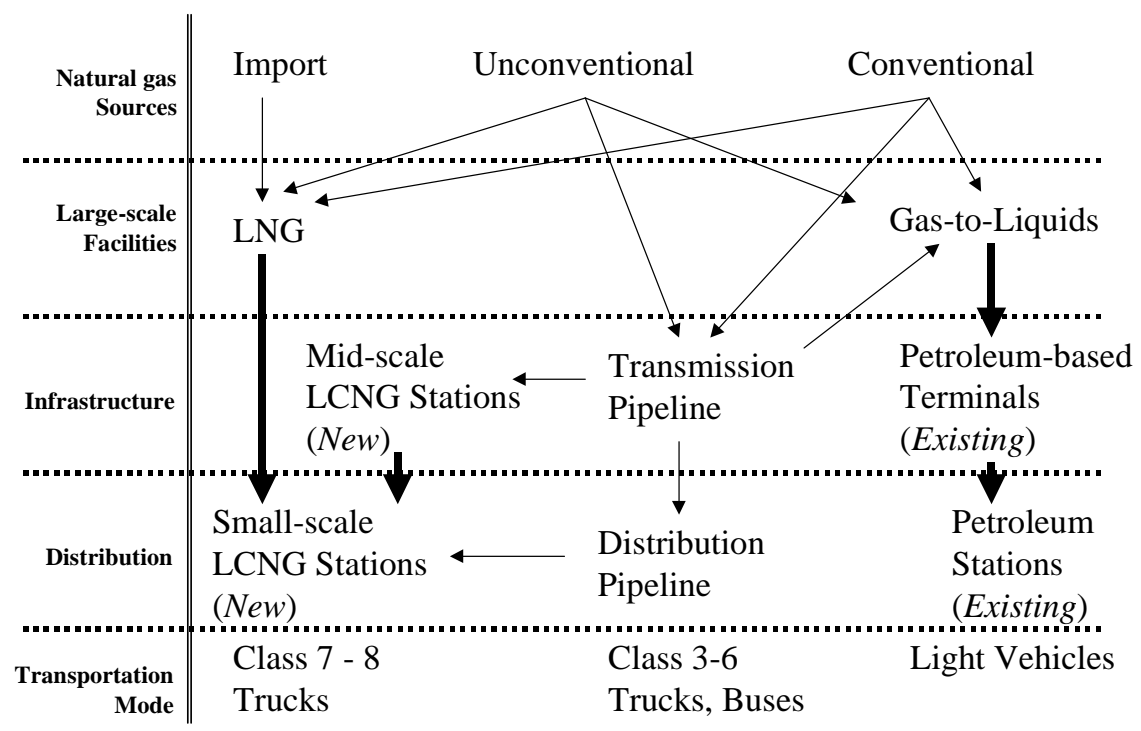

Figure 1. Liquefied natural gas production and refueling options

LIQUID NATURAL GAS PRODUCTION - Figure 1 shows the pathways for natural gas to enter the transportation modes of heavy trucks, buses, and light vehicles. Natural gas is transported either by pipeline or truck. The paths illustrated with bold arrows require overthe-road transport of the fuel. Figure 1 also shows the gas-to-liquid option which has the advantage of using existing infrastructure and distribution systems. LNG production may be categorized into three scales based on capacity: (1) small scale liquefiers producing under 10,000 gallons per day; (2) medium scale systems ranging from 10,000 to 70,000 gallons per day; and (3) large scale systems over 70,000 gallons per day. Small scale systems can be used to liquefy natural gas directly from the pipeline distribution network. Mid-scale liquefiers can produce LNG from landfill (unconventional) gas or at pressure letdown valves. Cryogenic plants and peakshaving facilities are considered large scale. Utility peakshaving facilities liquefy and store pipeline natural gas during off-peak periods to supplement gas use during peak periods. These types of large LNG production facilities as well as imports could potentially provide LNG to transportation customers. Under the DOE/BNL program various options are being explored for producing and supplying low-cost LNG to the transportation sector. Of particular interest is the cost comparison of local small-scale production with the purchase and delivery from remote mid- or large-scale liquefiers.

Unconventional and domestic gas sources such as landfill gas, stranded gas reserves, and sewage treatment plants are low-cost feedstocks for LNG. Unconventional gas recovery can have the effect of decoupling the price of natural gas from the price of imported oil because fleet owners can either buy stranded gas reserves or purchase long-term natural gas contracts from landfill owners. The need for small to medium scale liquefiers is to harness these vast unconventional energy sources.
To be competitive as a transportation fuel, natural gas technologies must be economically attractive and userfriendly. The costs of producing, storing and delivering LNG are critical considerations when calculating the economic equation. In most cases, LNG is not now available locally and must be transported from large scale facilities in other regions. Consequently, a significant portion of the price of LNG is for transportation of the fuel to the end-user. As an example, because there are no major LNG production or peakshaving facilities in the state of California, the price of delivered LNG ranges from a low of $\$ 0.43 / \mathrm{LNG}$ gallon (\$ $0.70 /$ gallon gasoline equivalent, GGE) to more than $\$ 1.00 /$ LNG gallon (\$1.63/GGE) [5]. Furthermore, California has plans for increasing the number of its LNG fleet vehicles. To meet this demand, LNG must be transported from nearby states. The near term demand is estimated to be about $36,000 \mathrm{gal} /$ day and is expected to increase by 40,000-50,000 gal/day. These additional vehicles are being introduced during the period 1999 - 2000 under California's new funds ( $\$ 37$ million) for medium and heavy duty vehicle projects [6].

Under a DOE contract, Acrion Technologies, Inc. has developed a cost-effective process for cleanup and recovery of $L N G$ and liquid carbon doxide $\left(\mathrm{CO}_{2}\right)$ from landfill gas [7]. Municipal landfill gas consists mainly of methane and carbon dioxide with up to several thousand parts per million of contaminants. Acrion's patented process uses liquid $\mathrm{CO}_{2}$, produced on site, to absorb and remove the contaminants from the landfill gas. The process involves compression, drying, $\mathrm{CO}_{2}$ wash contaminant removal, liquid $\mathrm{CO}_{2}$ recovery, residual $\mathrm{CO}_{2}$ removal, and methane liquefaction. Residual $\mathrm{CO}_{2}$ removal schemes use methanol absorption, membranes, and molecular sieves. An economic feasibility study was done to evaluate three process models for converting 2.0-5.0 million standard cubic feet per day (MMSCFD) of raw landfill gas into 8,700 - 21,800 gallons of LNG per day. Based on these models and taking credit for liquid 
$\mathrm{CO}_{2}$ production, it is estimated that $L N G$ can be produced at a cost of $\$ 0.10$ per gallon. An economic analysis of the process indicates a payback period of 3-5 years at selling prices of $\$ 0.40 / \mathrm{gal}$ of $L N G$ and $\$ 40$ / ton of $\mathrm{CO}_{2}$ [8] To date, Acrion has successfully demonstrated the technology in a pilot-scale system at the Al Turi Landfill, (Goshen, N.Y.). Phase II activity includes the selection of a site for full-scale (prototype) demonstration of the technology.

With funds from DOE and collaboration with the Gas Research Institute (GRI) the Institute of Gas Technology (IGT) is developing a cost-effective, natural gas liquefier for small, portable applications with production rates of less than 3,000 gallons per day. The project consists of process design and testing of a novel mixed refrigerant system with a single-stage, mass-produced compressor. To date, IGT has investigated various refrigerant mixtures, and selected and installed the liquefier's heat exchanger and compressor. The compressor selected is an open drive twin screw compressor (manufactured by Carlyle) that costs about $\$ 5,000$ including lube and safety equipment. Initial tests have demonstrated the capability to produce LNG at $\$ 0.30 / \mathrm{LNG}$ gallon assuming electricity cost of $\$ 0.08 / \mathrm{kWh}$. The project's next goal is to reduce this cost in half by improving efficiency and replacing electricity with lower cost, natural gas as the primary energy source. In addition to recovering stranded gas, these liquefiers offer advantages when combined with refueling stations. This topic will be discussed in more detail at the end of this paper.

NATURAL GAS STORAGE - The DOE/BNL program considers various technologies for natural gas storage: (1) liquefied natural gas (LNG) primarily for medium and heavy vehicles, and (2) compressed natural gas (CNG) and adsorbent natural gas (ANG) for light vehicles. Most natural gas vehicles run on compressed natural gas stored onboard in cylindrical tanks at pressures of 21-25 MPa (3,000-3600 psi). CNG's performance limitation is in its storage capacity and consequent driving range. The economic limitation Is the cost to dispense CNG. ANG systems which store gas in microporous adsorbents provide for a low-pressure alternative to high-pressure compressed gas storage. The CNG and ANG projects have been included in this paper to provide an overview of all the alternative $R \& D$ technologies being pursued in the area of natural gas storage.

A project conducted by the Atlanta Gas Light Adsorbent Research Group (AGLARG) explored adsorption technology for onboard vehicle storage. Their Adsorbent Natural Gas (ANG) storage system operates at low (3.4 $\mathrm{MPa}$ or $500 \mathrm{psi}$ ) to medium (6.9 MPa or $1000 \mathrm{psi}$ ) pressures as an alternative to high pressure $(25 \mathrm{MPa}$ or 3600 psi) CNG storage systems. Research efforts have focused both on developing low-cost microporous adsorbent materials and on fabrication of a conformable tank for the fuel and adsorbent [9]. AGLARG has successfully demonstrated this advanced ANG system on two light duty vehicles provided by Chrysler Corp. At 3.4 $\mathrm{MPa}(500 \mathrm{psi})$ the adsorbent material can deliver nearly 150 volumes of natural gas per volume of storage tank (measured as V/V). With lower pressures, less energy is required to compressed the natural gas. On a volumetric basis, ANG can store at $3.4 \mathrm{MPa}$ (500 psi) two-thirds the amount of gas as CNG at $25 \mathrm{MPa}(3600$ psi). AGLARG and a major automotive company plan to evaluate the ANG and conformable tank system in a concept car in the year 2000.

In order to address the need for greater storage and driving range for CNG systems, Thiokol Corp. was contracted to develop a high pressure, conformable natural gas tank. Through tank reshaping and liner materials development, Thiokol has achieved a system that offers $40 \%$ more onboard vehicle fuel storage compared to conventional gas cylinders [10]. Thiokol is performing a costing and feasibility study to determine the best options for manufacturing the tanks. Next year's task is to certify these tanks to the ANSI/ISA NGV2-1998 standard that addresses durability and safety issues for compressed natural gas vehicle fuel tanks.

The benefits of LNG include low pressure storage and greater energy density per volume. As a result LNG has the greatest potential for medium-heavy duty applications where users require low-cost, low-weight fuel storage options with increased driving range. Most LNG power systems available today which include engine and onboard fuel storage systems for Class 8 trucks have an incremental weight penalty of $140-230 \mathrm{~kg}$ (300-500 lbs). The incremental cost of a new LNG engine and fuel storage system ranges from $\$ 20,000$ - $\$ 45,000$ over the cost of a conventional diesel system. The cost of the cryogenic storage tanks alone can amount to over $50 \%$ of the incremental cost.

Addressing the problem of the high cost of LNG tanks, DOE/BNL contracted with Snyder Tank Corporation to develop a next generation of advanced storage tanks with improved thermal performance and reduced costs. Thus far, Snyder has developed a three-tank bus system, in which each tank has $0.23 \mathrm{~m}^{3}$ ( 60 gallons) capacity, that costs $42 \%$ less than other systems for the same driving range of about $595 \mathrm{~km}$ (370 miles). With their design, the storage system weighs nearly $454 \mathrm{~kg}(1000 \mathrm{lb})$ less than other LNG systems. Snyder's tanks have been evaluated and accepted for use by Nova Bus (New Mexico) which will be supplying LNG buses to the Dallas Area Rapid Transit (DART). Future activities for Snyder include acceptance testing of their $0.38 \mathrm{~m}^{3}$ (100 gallon) LNG tanks for Class $7 \& 8$ trucks.

FUEL DELIVERY SYSTEMS - As briefly discussed in the previous section, there are benefits to low pressure fuel storage for both onboard vehicle and refueling stations. However, there is a mismatch when these low pressure systems are coupled to high-pressure fuel injectors that are needed in tomorrow's efficient natural gas engines. To meet these types of problems, DOE/BNL 
is funding projects on pressure-build systems for LNG storage systems. Two types of onboard fuel delivery system are considered under this program. The first configuration entails medium pressure LNG. In this configuration, fueling of $L N G$ to the engine will not require a pump, provided that the tank's pressure is above the engine's fuel-pressure requirement. In the second design, the fuel is stored in a low pressure tank and then must be pressurized to achieve the high pressure requirements of the engine design (ie. from 0.7 to 25 $\mathrm{MPa}, 100$ to $3600 \mathrm{psi}$ ). For this configuration, Beck Engineering has designed and is testing an onboard, cryogenic LNG pump. The Beck pump design offers small heat leaks and vapor recovery, noncontacting and long-life bearings, and is insensitive to cavitation. Ongoing tests are being conducted to evaluate the pump at the design and off-design operating conditions.

For heavy vehicle engines (typically $500 \mathrm{hp}$ or less) the power output from a natural gas engine is lower than the diesel counterpart with the same frame. It is known that second-stage intercooling of intake air adds to the engine's power output. For LNG vehicles this fact can be used to increase the air density by cooling the intake air with LNG, as illustrated in Figure 2. The potential advantages of this concept include downsizing engine rating for the same performance and lower cost. This concept allows for some of the energy used to produce LNG to be recovered in achieving better engine performance. As part of the first phase of their project, Advanced Technologies Management has completed the design of its second-stage intercooler. The intercooler uses propane as the intermediate fluid for exchanging heat between the LNG and turbocharged air. This design prevents icing of surfaces which would be problematic with direct heat transfer between LNG and the intake air. The intercooler is designed to be modular, low cost, low weight, and easy to install for new and retrofit natural gas engines. An engine test facility has been set up and testing has begun to demonstrate engine power improvements. The proposed future activities include integrating a simply designed second-stage intercooler with the truck's existing first-stage intercooler (radiator) to minimize total weight, complexity, and cost.

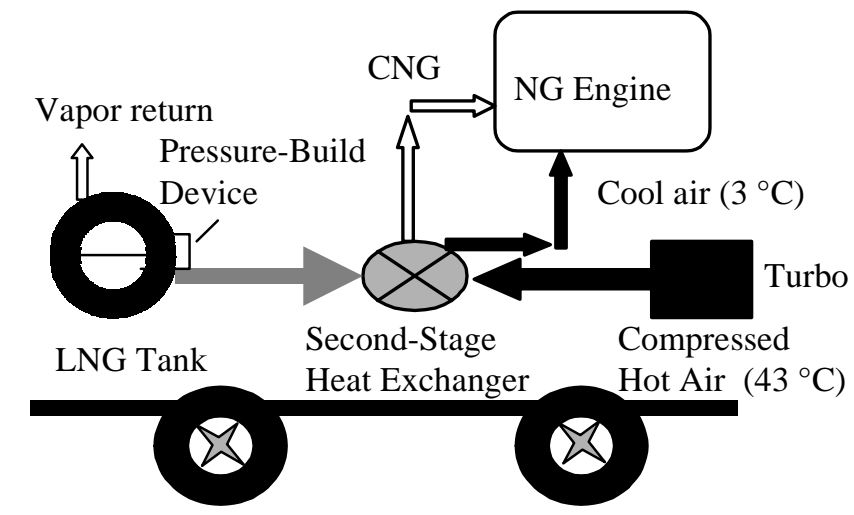

Figure 2. Second-stage intercooling of engine intake air with LNG
One approach to reduce infrastructure cost is to generate a high pressure supply of natural gas by pumping and vaporizing LNG. This approach would allow a single natural gas station to refuel both CNG and LNG vehicles. This concept is referred to as a liquefied-compressed natural gas (LCNG) refueling station. An LCNG layout drawing is shown in Figure 3.

A CNG station is compressor based and an LCNG station requires a cryogenic LNG pump and LNG storage tanks. Generally, compressor-based CNG stations have both high capital and operating costs. In comparison, the LCNG station has high capital but low operating costs. This is due in part to the high cost of cryogenic tanks. The relatively lower operating costs of LCNG stations are due its lower power requirements. Less energy is required to raise the pressure of a liquid than a gas. The power necessary to raise the pressure of LNG to $28 \mathrm{MPa}$ (4000 psi) is $1 / 8^{\text {th }}$ of that needed to compress the same amount of gas to the same pressure. LNG storage tank costs are directly related to their storage capacity. As a rule of thumb, for large tanks they are related by a factor of ten. For example, a $53 \mathrm{~m}^{3}$ (14,000 gallon) tank costs about $\$ 140,000$. To make a capital and operating cost comparison between these two types of natural gas refueling stations is difficult since the liquefier costs are usually not included, and yet compressor costs are included in some studies. However, comparing a $53 \mathrm{~m}^{3}$ (14,000 gallon) capacity LNG station with a 28 SCMM (1,000 SCFM) CNG station does provide some insights into the infrastructure costs. The capital cost of an LCNG station with 1,000 SCFM refueling capability, 14,000 gallon LNG storage, and high pressure cascade gas storage tanks is only slightly less than the capital cost of a CNG station with the same refueling capacity (via a gas compressor) and cascade gas storage [11]. This comparison assumes that both of the respective stations have access to delivered LNG and pipeline gas. Regardless of the methods used in the various cost analyses, it is clear that with greater fueling capability the LCNG station could have greater payback. In addition, the capital cost of LCNG stations can be reduced by minimizing the need for storing LNG. This can be accomplished by replacing some of the LNG storage tanks with small scale, low-cost liquefiers. This type of arrangement is discussed in further detail in the next section.

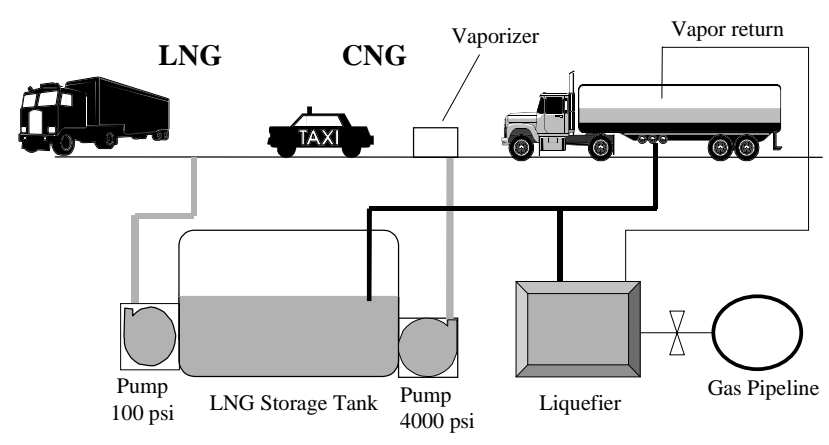

Figure 3. LCNG refueling station concept 
In promoting LCNG development, funding has been provided to CVI Corporation to convert an existing LNG facility located in Washington, PA to an LCNG refueling station. This station will then be capable of delivering both liquid and compressed natural gas. CVI is modifying a high-pressure cryogenic pump to operate inside an existing underground insulated storage tank. The station features fully automated operations that minimize boil-off. The submersed cryogenic pump is capable of delivering LNG at 13 liters per minute (3.5 gallon per minute, GPM) at $31 \mathrm{MPa}(4500 \mathrm{psi})$.

MARKET STRATEGY/ END-USE - The DOE/BNL alternative fuel market strategy consists of working with the gas industry and supporting local/state efforts in introducing natural gas vehicles to their regions.

California has the nation's largest market for motor vehicles and the most severe air pollution problems. Hence, it is also the leader in implementing the most progressive programs in clean fuel vehicles. CALSTART, a non-profit consortium developing advanced transportation technologies, is assessing the market opportunities for LNG technology in California through the DOE/BNL program.

Under the first phase, CALSTART has just completed a feasibility study [5] on using LNG as a heavy vehicle and equipment fuel at the California seaports of Los Angeles and Oakland. The analysis focused on Class 7 and 8 trucks and the heavy-duty shipping and rail terminal container handling equipment currently powered with diesel engines. Based on the characteristics of the ports' trucking and terminal operations, and an assessment of the current state of LNG technology, CALSTART identified significant barriers to the use of LNG at the ports and mitigation strategies that could aid in overcoming these obstacles. Their findings indicate that LNG use at the ports is technologically feasible, environmentally beneficial, and is the most viable alternative to diesel for heavy-duty applications. However, there are significant logistical constraints and the economics of LNG use are questionable under the current price structure. In Phase II of this project, CALSTART will assess the feasibility of implementing the key mitigation measures and will identify potential demonstration projects within California. CALSTART is also exploring the potential for using natural gas to power marine vessels. Marine vessels represent a source of air pollution in the U.S. coastal areas and waterways. Under Phase II of their project, DOE/BNL is supporting this effort as part of a larger project administered by the U.S. Maritime Administration. The work consists of converting the U.S. Merchant Marine Academy training vessel (Kings Pointer) from diesel to dual-fuel (natural gas/ diesel) power. The objective of the program is to compare diesel and natural gas emissions characteristics.
In support of New York State's alternative fuel program, DOE/BNL is funding several studies to assess the potential utilization of natural gas resources found within the state. The Environmental Business Association of New York State (EBA/NYS) is reviewing the quantity and quality of natural gas reserves for economic development and commercialization. Potential incentives and scenarios will be evaluated that might promote investment in infrastructure or sale of natural gas. Vandor \& Vandor has recently completed a study that identifies landfills and sewage treatment plants for producing natural gas for transportation. This paper study identifies reclamation and small-scale liquefaction technologies, gas-cleanup systems, and economic opportunities within NY State and Maryland [5]. The Greater Long Island Clean Cities Coalition has been tasked with evaluating the feasibility of implementing an LNG vehicle equipment testing program on Long Island, N.Y.

In Texas, Lone Star Energy is being funded to develop a plan for the siting and operating of new LCNG fueling facilities. These stations are being designed for ease of operation and "transparency." This project is part of a much broader effort being led by the Texas General Land Office to develop a network of alternative fuel stations throughout Texas and the Southwest. A partnership of federal, state and local agencies, private fleet operators, vehicle/engine manufacturers, fuel suppliers and the North American Superhighway Coalition has been formed to assist in these efforts. The U.S. Postal Service is considering Texas for an "anchor fleet" of natural gas postal trucks. The three long term goals of this project are to demonstrate LCNG technology, to secure the deployment of additional natural gas vehicles, and to create fueling and support infrastructure along clean corridors in Texas.

The DOE in partnership with the Gas Research Institute, awarded three contracts to develop market strategies and products that would be valuable to LNG users. ARCADIS will be developing a marketing kit for the promotion of LNG in heavy vehicle purchase and use in California. The Physical Science Laboratory of New Mexico State University will provide a standards document that addresses planning, zoning and code enforcement issues for the installation of LNG refueling stations. Battelle will be generating a users guide for fleet owners and operators that addresses the permitting process and startup operations of LNG and LCNG stations. 


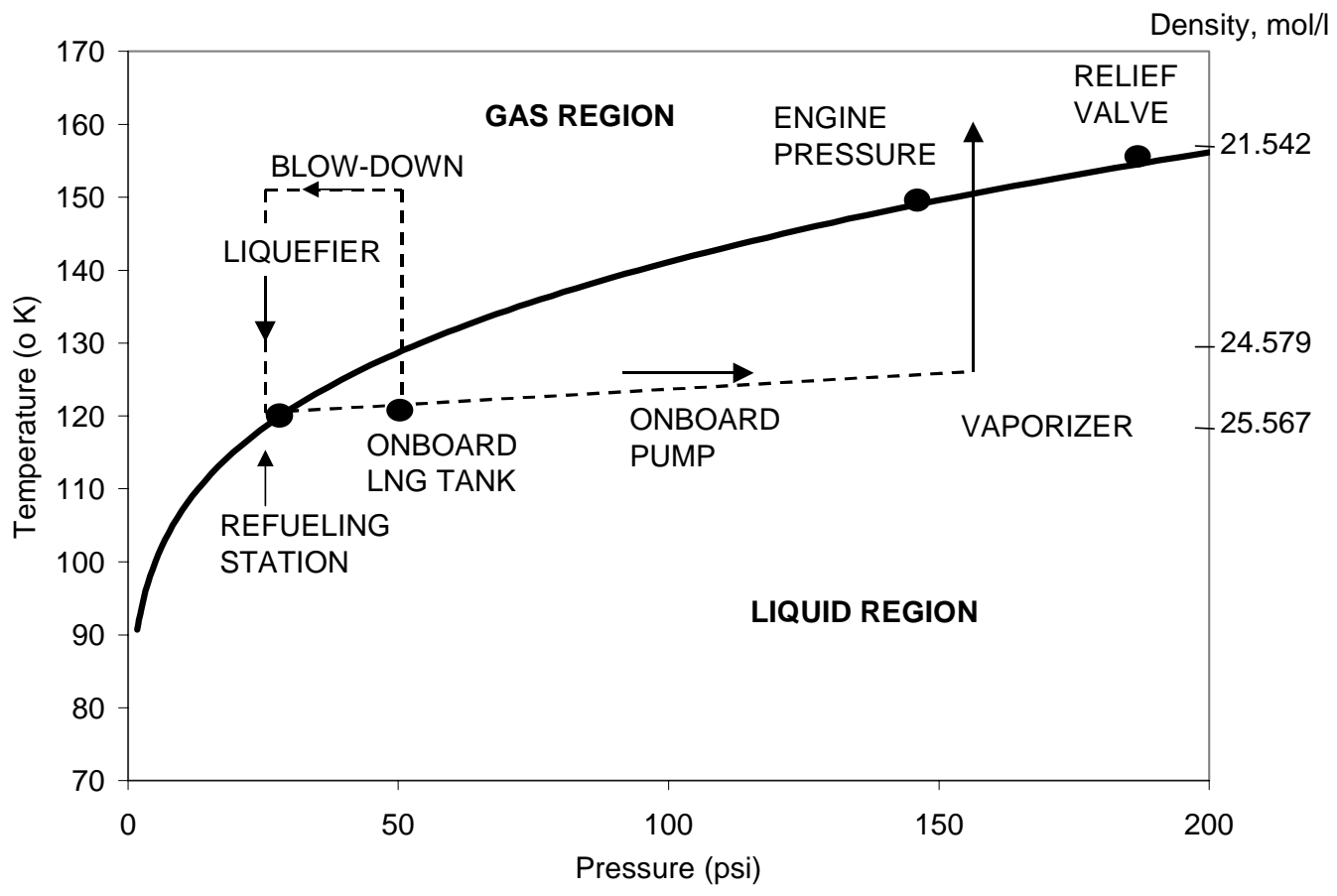

Figure 4. Methane saturation liquid curve showing an approach to integrate onboard storage with refueling

\section{SYSTEMS INTEGRATION ANALYSES}

The key to reducing costs and improving efficiencies is through systems integration of individual technologies. One technique to integrating onboard liquid natural gas storage and refueling systems is to handle LNG as a subcooled liquid. Figure 4 illustrates this approach by showing the saturated vapor-liquid curve for methane. Superimposed on this curve are the possible operating temperatures and pressures for the refueling station, tank, vaporizer, relief valve, and engine. LNG becomes a subcooled liquid by pressurizing it from its saturated condition. There are advantages to operating within the subcooled liquid region. The density of LNG increases as temperature decreases. The densities for saturated methane at typical minimum and maximum LNG storage conditions are $25.57 \mathrm{~mol} / \mathrm{l}(120 \mathrm{~K}, 0.19 \mathrm{MPa}$ or $28 \mathrm{psi})$ and $21.54 \mathrm{~mol} / \mathrm{l}(156 \mathrm{~K}, 1.37 \mathrm{MPa}$ or $200 \mathrm{psi})$, respectively. Within this range almost $19 \%$ more fuel can be stored at the lower temperature, which extends the vehicle's driving range. Alternatively, fewer storage tanks are required for the same driving range, which reduces the vehicle's weight and cost. Operating in the subcooled region and not on the liquid-vapor saturation curve minimizes boil-off. Figure 4 also shows a vapor return line which allows for recovery of the vapor upon pressure release of the tank (blow-down) when refueling. This vapor can then be reliquefied at a refueling station that has a small liquefier. In this manner the cycle Is completed from production to engine use with no vapor loss due to venting.

Three elements of the system integration analysis are:

1. The first strategy is to combine liquid and compressed natural gas (LCNG) refueling at the same station. There are several noteworthy advantages of having multifuel capabilities, including greater total volume of natural gas dispensed and reduced cost due to integrating and optimizing two separate refueling systems into one. Although natural gas vehicles that use CNG far outnumber vehicles fueled by LNG, it makes more sense to develop the infrastructure for the high fuel users (ie. heavy vehicles). Another benefit is the more consistent fuel quality which can be attained following the liquefication of natural gas. A comparison between CNG refueling station vs. LCNG (pump with vaporizer, no compressor) shows a cost saving of $\$ 0.24 / \mathrm{MMBtu}[8]$ in favor of LCNG.

2. There is a benefit in combining a small scale liquefier with an LCNG station. This scenario has been illustrated in Figure 3. About $30 \%-50 \%$ of the cost of a small to medium scale natural gas liquefaction system is associated with storage tanks. Typical costs for tanks range from $\$ 100,000-\$ 200,000$ for $10,000-20,000$ gallon storage tanks. Small liquefiers cost between $\$ 100,000-\$ 300,000$. Reducing the need for onsite storage of LNG is a means of reducing costs. Other derived benefits include reducing liability and improving safety, which facilitate siting and reduce overall costs. Small scale liquefaction systems also allow for production of LNG on an as-needed basis, and as a result improve the reliability of obtaining product.

3. The benefit to refueling a vehicle at a station that has a small liquefier is that evaporative emissions or boiloff can be eliminated. This is done by having a vapor return line from the onboard tank back to the refueling station. This in effect eliminates any possible methane (a greenhouse gas) emissions. 


\section{CONCLUSIONS}

The interests, goals, status and accomplishments of the Office of Heavy Vehicles Technologies natural gas vehicle program have been presented in this paper. Wherever possible these technologies have been integrated together to give a cradle to grave overview of natural gas utilization for the transportation energy sector. Energy security remains DOE's first priority. However, any replacement fuel for imported petroleum must help solve air quality problems. Since natural gas is a clean burning fuel, the major barrier to its increased usage is the current low price of imported oil. The strategies being pursued with the DOE/BNL natural gas vehicle program are to improve the existing technology, to help develop the Infrastructure and reduce its costs. As oil prices rise the demand for NGVs will also rise. The direction of the program has been towards improving LNG storage and delivery systems, promoting market competition, simplifying the siting and permitting of natural gas refueling stations, developing technologies for the recovery of unconventional gas reserves, and supporting industrial standardization of LNG use. In summary, the government is interested in natural gas because it is a clean alternative fuel to imported oil. The public will only be interested in natural gas as a vehicular fuel if it costs less than petroleum and is as user-friendly.

\section{ACKNOWLEDGMENTS}

This work was done under contract no. DE-AC02$98 \mathrm{CH} 10886$ with the U.S. Department of Energy.

\section{REFERENCES}

1. Wegrzyn, J., et.al., "DOE/BNL Liquid Natural Gas Heavy Vehicle Program," Future Transportation Technology Conference \& Exposition, Costa Mesa, CA, August 11-13, 1998, SAE Paper No. 981919.

2. EIA Annual Energy Outlook, Federal Highway Administration, Highway Statistics, 1998.

3. Oppenheimer, A., "Natural Gas Enhanced Efficiency Engine," 1999 SAE Government/Industry Meeting, Washington, D.C., April 26-28, 1999, SAE Paper No. 1999-01-2247.

4. Liquefied Natural Gas as a Transportation Fuel for Heavy-Duty Trucks, National Renewable Energy Laboratory, December 1997, NREL/SR-540-23094.

5. "Seaport Liquid Natural Gas Study", Final report prepared by CALSTART-WestStart (Pasadena, CA) for Brookhaven National Laboratory, Upton, NY, February 1999, BNL No. 66527.

6. Private communications with G. Pope, USA PRO, Huntington Beach, CA, December 3, 1998.

7. "Landfill Gas for LNG Swap Sought by New York Company," LNG Express, April 1999.
8. "Landfill Gas Conversion to LNG and LC02," Final Report prepared by Acrion Technologies, Inc., (Cleveland, $\mathrm{OH}$ ) for Brookhaven National Laboratory, Upton, NY, February 1999, BNL. No. 66525.

9. Home, D., 'The Low-Pressure Option," Natural Gas Fuels, March 1998.

10. Golde, R., et.al., "The Shape of Things to Come," SAMPE Journal, Society for the Advancement of Material and Process Engineering, March/April 1999.

11. LNG Vehicle Markets and Infrastructure, Report prepared by Zeus Development Corp. (Houston, TX) for Gas Research Institute, March 1998, GRI No. 